7-24-2019

\title{
Hemispheric and Continental Scale Patterns of Similarity in Mountain Tundra
}

George P Malanson

University of Iowa

Risto Virtanen

University of Oulu

Andrea J Britton

James Hutton Institute, Aberdeen

Please see article for additional authors.

DOI: https://doi.org/10.17077/u06a-840z

\section{Copyright (C) 2019 the authors}

\section{Comments}

AJB was funded by the Rural and Environment Science and Analytical Services Division of the Scottish Government

Hosted by Iowa Research Online. For more information please contact: lib-ir@uiowa.edu. 
3 George P Malanson ${ }^{1 *}$, Risto Virtanen ${ }^{2}$, Andrea J. Britton ${ }^{3}$, Borja Jiménez-Alfaro ${ }^{4}$, Hong Qian ${ }^{5}$,

4 Alessandro Petraglia ${ }^{6}$, Marcello Tomaselli6 ${ }^{6}$ David Cooper ${ }^{7}$, Christian Damm ${ }^{8}$, Richard H

5 Pemble ${ }^{9}$, Robert B. Brett ${ }^{10}$

6

71 University of lowa, lowa City, IA 52242 USA

82 University of Oulu, 90014 Oulu, Finland

93 James Hutton Institute, Aberdeen, AB15 8QH Scotland

104 Universidad de Oviedo, 33600 Mieres, Spain

115 Illinois State Museum, Springfield, IL 62703 USA

126 Università di Parma, 43124 Parma, Italy

137 Colorado State University, Fort Collins, CO 80523 USA

148 Karlsruher Institut für Technologie, 76021 Karlsruhe, DEU

159 Minnesota State University, Mankato, MN 56001 USA

1610 Snowline Ecological Consulting, Whistler, BC V0N 1B0 Canada

17

18 *corresponding author: george-malanson@uiowa.edu

20 Acknowledgments. AJB was funded by the Rural and Environment Science and Analytical 21 Services Division of the Scottish Government. 


\section{Abstract}

25 Understanding the full range of biodiversity patterns from local to global scales, through the

26 study of the drivers of multiscale plant community composition and diversity, is a current goal of

27 biogeography. A synthetic understanding of to what extent vegetation compositional patterns are

28 produced by biotic factors, geography or climate and how these patterns vary across scales is

29 needed. This lack hinders prediction of the effects of climate change in global vegetation.

30 Variation in community composition is examined in relation to climatic difference and

31 geographic distance at hemispheric and continental scales. Vascular plants and bryophytes in 13

32 mountain regions were analyzed; eight in Europe and five in North America, nine mid-latitude

33 and four oroarctic. Species composition differed between continents and between oroarctic and

34 mid-latitude regions. Patterns of paired regional similarity with distance were significant for all

35 pairs and intercontinental pairs, but not for those within Europe and North America. Climatic

36 variables accounted for most of the variance in vegetation patterns revealed by General Linear

37 Models of ordinations, but geographic variables, of Moran eigenvectors and latitudinal zones,

38 were also important and significant. The effects of geography were typically twice as strong for

39 vascular plants as for bryophytes. The importance of geography at these scales suggests that past

40 evolutionary and ecological processes are as important as current fit to any climatic niche.

41 Interpretation of observations of the impacts of global climate change should recognize

42 geographic context and phylogeny, and policies to mitigate them, such as assisted migration,

43 should be cautious.

44

45 Key words: alpine; beta diversity; climate, distance; oroarctic

46 


\section{Background and objectives}

The biodiversity of mountain tundra, encompassing both alpine and oroarctic tundra (the

49 latter is tundra at high latitudes where the effects of elevation differentiate it from arctic tundra;

50 Virtanen et al. 2016) is globally higher than expected (Körner 2000). Mountain tundra diversity

51 is also regarded as threatened due to anthropogenic climate warming, and several studies

52 document recent changes in high elevation plant diversity (e.g., Britton et al. 2009, Spasojevic et

53 al. 2013, Lesica and Crone 2017, Steinbauer et al. 2018). These observations imply that patterns

54 and processes underlying mountain plant assemblages may be spatially structured, producing

55 strong heterogeneity in possible plant responses to climate change (e.g., Anthelme et al. 2014).

56 Therefore, although first described by von Humboldt and Bonpland (1805), and despite a

57 growing body of observations on the patterns of alpha and beta diversity (respectively, the

58 diversity of species at local sites and the change in species composition among such sites) on

59 environmental gradients in mountains (e.g., Kikvidze et al. 2005, Löffler and Pape 2008, Li et al.

60 2011, Elmendorf et al. 2012, Gritsch, Dirnböck and Dullinger 2016, Harbert and Cooper 2017,

61 García-Gutiérrez et al. 2018), a better understanding of the large-scale spatial variation in

62 mountain plant assemblages is crucial to better dissect possible climate-plant relations and

63 responses to future climate change.

64 The importance of changing scales is now a central principle of physical geography

65 (Meentemeyer 1989, Walsh et al., 1997, Malanson et al., 2017) (we use scale in the most

66 common way, as equivalent with extent, and so large scale covers larger areas). McGill (2010)

67 argued that understanding scale dependence was needed to explain biogeographic patterns. He

68 highlighted four controls on the distributions of species: climate, species interactions, habitat,

69 and dispersal. Although he hypothesized climate and dispersal as operative and possibly equally 
70 important at both the smallest and largest scales, climate operates at small scale only as

71 microclimate, and microclimate is the result of the macroclimate being modified by habitat and

72 the organisms themselves (plants in most cases). At the scale of the globe, climate does not

73 differentate distributions because climates repeat in patterns determined by gradients of latitude

74 and continentality, and so climate effects are confined to continental to hemispheric scales.

75 Dispersal can make a difference at small scale through a mass effect, but it dominates processes

76 at the largest, global, scale. This sequence in which processes would dominate the structuring of

77 species patterns on a gradient of increasing spatial scale would then be simplified: biotic

78 interactions - habitat - climate - dispersal. Furthermore, without observations in the past, our

79 understanding at larger scales is inferred from long-term biogeographic patterns (e.g., Douda et

80 al. 2018) that are represented by geographic distance and isolation; these serve as a proxy for

81 observations of dispersal.

82 Large-scale compositional patterns in mountain vegetation reflect historical speciation-

83 extinction dynamics (Hewitt 1996, Hoorn et al. 2013), Tertiary continental dynamics (Wolfe

84 1987), regional extinction-immigration dynamics (Riebesell 1982, Hadley 1987, Harris 2007),

85 large-scale climatic niche processes (Virtanen et al. 2016), and spatial processes related to

86 geographic distance (Taylor 1977, Malanson, Cheney and Kinney 2015, Clarke et al. 2018). As a

87 result, the relationship of mid-latitude alpine tundra to arctic tundra is not a simple gradient of

88 difference with latitude (e.g., Billings 1973, Virtanen and Eurola 1997, Virtanen et al. 2016).

89 Moreover, studies find that plant community relations to environment vary with the scale of

90 analysis (e.g., Kim et al. 2012), including alpine communities (e.g., Suding et al. 2015,

91 Chalmandrier et al. 2017). The relevance of geographic scale for local and regional diversity was

92 illustrated by Malanson, Fagre and Zimmerman (2016, 2018), who showed that the drivers of 
93 beta and alpha diversity differed among four regions across the Rocky Mountains in the USA. In

94 summary, due to their topographic complexity, steep environmental gradients, and mix of habitat

95 types, mountain tundra varies as much within geographic units (valleys and slopes) as among

96 them. The explanations for the beta diversity at continental scales may be related to climate, but

97 biogeographic history and the geographic separation of mountain tundra regions should also play

98 a role.

99 Understanding the processes influencing alpine tundra beta diversity across multiple

100 scales is important for anticipating the effects of ongoing climatic change (Socolar et al. 2016).

101 Potential mitigation, such as assisted migration (fourth among five categories of increasing

102 intervention outlined by Malanson et al. 2019), would depend on biogeographic insights (Hewitt

103 et al. 2011, Abeli et al. 2014). Factors that make anticipation and thus mediation problematic,

104 however, include uncertainty about the relative importance of climate as a determinant of beta

105 diversity given the varying spatial and temporal context and relatively high beta diversity

106 (Opedal, Armbruster and Graae 2015, Stivrins et al. 2016).

107 Here, we take a first step towards improving knowledge of the large-scale biogeographic

108 patterns of mountain tundra assemblages and how they relate to space (geographic distance) and

109 climate. We compiled data from Europe and North America and examined variation in plant

110 community composition in oroarctic and mid-latitude mountain tundra as it is related to variation

111 in climatic variables and geographic distance. Variation in concert with climate is expected

112 because energy and water resources, and their relevant variables such as temperature and soil

113 moisture, are important dimensions of species distribution or niche. We believe that geographic

114 distance matters because it is a proxy for processes that have occurred in the past that we cannot

115 observe; these include responses to past climate changes and disequilibria (e.g., Douda et al. 
116 2018), including dispersal (Malanson et al. 2017). For example, Muster et al. (2009) revealed

117 that genetic links between Scandinavian, Alp, and Carpathian spiders could be explained either

118 by low rates of current dispersal or high dispersal rates at the Last Glacial Maximum (LGM), and

119 patterns of plant endemism and refugia also reflect disequilibria (e.g., Patsiou et al. 2014,

120 Smycka et al. 2017). Plant community composition could reflect responses to past climatic

121 conditions (e.g., Kammer, Schöb and Choler 2007), extending to the LGM, where niche

122 constraints have not had time to be fully expressed.

123 Our main aim was to address intercontinental patterns in similarity in mountain tundra

124 vegetation in relation to spatial and climatic variables. Many environmental factors differ across

125 the mountain regions studied here. These include the environmental templates determined by the

126 geological processes of mountain building and the millennia of erosion under different climatic

127 regimes. We focused on distance and climatic difference as the potential factors that would

128 differentiate the floras in order to examine such factors at the broad scale in the context of the

129 framework provided by McGill (2010). The other factors that differentiate these mountain

130 regions, such as differences in substrates and soils, equally differentiate mountains within

131 regions and properly are within the domain of habitat differentiation at smaller scales as

132 hypothesized by McGill (2010). We contend that specific geographic characteristics will alter

133 the relationships with distance and climate; e.g., oroarctic communities will be more similar to

134 each other relative to those at mid-latitudes than distance or climate would dictate (cf. Virtanen

135 et al. 2016), and extremes of climate or isolation will lessen similarity due to endemism. Because

136 mountain tundra exists in a narrow range of temperatures, we also expected that water (e.g.

137 precipitation) rather than temperature would be principally responsible for climatic

138 differentiation. Additionally, we recognize a potential difference in responses for vascular and 
139 bryophyte taxa, because bryophytes disperse via spores, as opposed to the varied and larger

140 propagules of vascular plants, which leads to less geographic isolation over (possibly longer)

141 evolutionary time (cf. Ledent et al. 2019). We expect:

142 1: Similarity in plant communities among regions will be more related to geographic distance

143 than to climate; this relationship will be stronger for intercontinental than intracontinental

144 distances.

145 2: Patterns of similarity will be modified so that oroarctic communities will be more similar than

146 mid-latitude communities, after accounting for distance and climate.

147 3: Vascular species will have stronger relations with distance than bryophytes.

148 4: Among climate variables, similarity among regions will be more related to precipitation than

149 to temperature.

150 This knowledge is essential for understanding the similarities and dissimilarities in processes

151 underlying the beta-diversity of plant communities at continental to hemispheric scale (e.g.,

152 Jimenez-Alfaro et al. 2018). It would also provide a base for investigating how diversity arises

153 and is maintained in terms of the importance of current niches and past changes.

155 Methods

156 Data sources and selection

157 Species data

158 We used records of species presence in multiple vegetation plots (relevés) from 13

159 regions in Europe and North America (Figure 1, Table 1; these data are publicly accessible at

160 ir.uiowa.edu). The regions were defined based on how earlier datasets were published; but each

161 covers a section of a mountain range within $1^{\circ}$ of latitude and longitude. We chose these regions 
162 because they had extensive coverage in numbers of plots for their areas, the data collection

163 methods were comparable, and in most cases consistently followed the Braun-Blanquet

164 methodology in the field (and in all cases used a visual estimate of percent cover in quadrats,

165 which we simplified to species presence). Places that were not considered were those that did not

166 use quadrats for sampling, compiled presence for entire ranges or communities rather than by

167 plot, or reported summaries only (e.g., syntaxa). We further excluded the sites from Virtanen et

168 al. (2016) that they had identified as arctic, and for Scotland we excluded those vegetation types

169 described by Averis et al. (2004) as non-montane and plots at elevations less than $675 \mathrm{~m}$, which

170 Birse $(1976,1980)$ set as the lower limit of alpine vegetation.

171 Because the observations were made at different times, all nomenclature was updated to

172 currently accepted taxonomy using the Taxonomic Name Resolution Service at iPlant

173 Collaborative (http://tnrs.iplantcollaborative.org); for unresolved species, we retained the

174 original nomenclature. We removed lichens from the analyses because their response to climate

175 may be the inverse of vascular species (Walker et al. 2006) and their taxonomic comparability in

176 the several data sources was low. We then divided the observations into vascular and bryophyte

177 datasets because we expected the two types of plants to respond differently to climate (Molau

178 and Alatalo 1998). We discarded records where only the genus was identified because for

179 comparing regions these would bias the results toward greater than actual similarity. Our final

180 dataset contained 397 bryophytes and 1814 vascular species on 4829 plots.

181 In order to have balanced comparisons in the analyses but retain the breadth of

182 observations, we reduced the data to 200 plots per region where more plots were available in a

183 region. To sample 200 plots from a larger pool, we ran detrended correspondence analysis

184 (DCA; using PC-ORDv6), an eigenvector ordination that represents the order of similarity on its 
185 primary axis, on the data for each region, and then sampled 200 plots via a regular systematic

186 selection along that axis so that the full range of plant communities would be represented. The

187 plots were approximately evenly distributed along this axis because the Braun-Blanquet

188 classification method, not used here, works better with that type of field sample. The final data

189 set included 2507 plots for vascular plants (with 1733 species) and 1751 plots for bryophytes

190 (with 361 species; the Betic, Cantabria, and Yosemite vicinity data had no bryophyte records).

191 Climate data

192 Because several of the regions did not have georeferenced plot data, we chose three

193 representative locations within each study area. The locations were midway between treeline and

194 summits. Using the latitude and longitude for these three points in the CHELSA climate dataset

195 (Karger et al. 2017; these are at 30-arcsecond resolution for 1979-2013), we took the average for

196 key bioclimatic variables: mean annual temperature, warmest quarter and coldest quarter mean

197 temperatures, and the annual and wettest, driest, warmest, and coldest quarter mean precipitation.

198 Geographic distance and spatial variables

199 We used the haversine method to calculate the great circle distances, in kilometers,

200 between points in the middle of each region. We calculated the mean distance among regions and

201 the summed distance to the three nearest neighbors as an indicator of isolation. Following Peres-

202 Neto and Legendre (2010) for dealing with distances among an array of points, we calculated

203 Moran spatial eigenvectors by applying principle coordinates analysis to the matrix of distances

204 between pairs of regions (also known as principle coordinate neighbor matrices).

205 Analyses

206 We used a Multi-Response Permutation Procedure (MRPP; McCune and Grace 2002), 207 with Sørenson (1948) similarity, to test for differences between continents, between latitudinal 
208 (oroarctic and mid-latitude) regions, and among continent-by-latitude regions. MRPP is an

209 alternative to discriminant analysis that avoids parametric assumptions. Sørenson similarity, the

210 proportion of species abundance shared between pairs of observations to their summed

211 abundance, has characteristics relative to shared species that makes it a peferred representation

212 (McCune and Grace 2002, Austin 2013).

213 We calculated the Sørenson (1948) similarity among all possible pairs of plots in our

214 data; We then calculated the mean similarity among the pairs of regions. We regressed the

215 similarity between pairs of regions on the distances between them, testing for significance of the

216 correlation using the randomization method proposed by Mantel (1967) (this analysis meets the

217 limiting criteria, similarity questions to which spatial eigenvectors do not apply, proposed by

218 Legendre et al. 2015). After preliminary analyses, we used an exponential fit for the vascular

219 species and a linear fit for the bryophytes. From the resulting patterns, we separated the pairs into

220 those between continents (long distances) and within continents and calculated and plotted

221 regressions. We then did the same for the within-continent pairs split between Europe and North

222 America. We also examined the differences in patterns and in the differences between vascular

223 and bryophyte similarities for the pairs of regions.

224 We ordinated the plot-species data by nonmetric multidimensional scaling (NMDS). We

225 determined the number of ordination axes to analyze by examining the correlation between the

226 distances among all pairs of plots in the dimensions of ordination space with the Sørenson

227 similarity matrix and increased the number of axes as long as the increase in correlation was

228 greater than 0.05 ; we ended using four axes (for visualization, we used the first three

229 dimensions). We regressed the means of the plot positions of each region on the four ordination

230 axes with the bioclimatic variables and the Moran eigenvectors scores. After examining all 36 
231 bivariate plots for nonlinear patterns, we used General Linear Models (GLMs) to fit stepwise

232 models (0.05 to enter, 0.10 to remove; $c f$. Draper and Smith 2014) with an overall $\mathrm{R}^{2}$ and per-

233 variable contribution. We used these metrics to estimate the relative importance of the climatic

234 and geographic variables.

235 Results

236 Bioclimates and geographic distances for regions

237 The data for the bioclimatic and geographic variables are shown in Tables 2 and 3. One

238 significant Moran eigenvector was found, and it appears to differentiate the more clustered

239 European ranges from those in North America.

240 Regions, similarity and distance

241 The MRPP (Table 4) revealed significant differences between the continents, the

242 latitudes, and the continent-by-latitude groupings; the low p values indicate the distinct

243 differences, although the magnitudes are small because within-group heterogeneity is high. The

244 greatest dissimilarity for vascular communities was between the European and North American

245 oroarctic, which contrasted with their low effect for bryophytes. For bryophytes, the mid-latitude

246 communites had the smallest dissimilarity while both of these continents differed from the North

247 American oroarctic.

248 Table 5 shows the mean Sørenson similarity for all pairs of regions. The correlation

249 between the average similarity of all pairs and the distances between them was $\mathrm{r}=-0.468(\mathrm{p}<$

2500.001 by Mantel test; 13 regions, $\mathrm{n}=78)$ for the vascular species and $\mathrm{r}=-0.406(\mathrm{p}<0.016 ; 10$

251 regions, $\mathrm{n}=45$ ) for the bryophytes. The relationship of similarity among pairs of regions to

252 distances among pairs of regions was exponential for the vascular species and linear for the

253 bryophytes (Figure 3). Although a number of positive-residual points appeared to be outliers, 
254 their removal did not improve the regression $\mathrm{R}^{2}$; these apparent outliers were pairs of oroarctic

255 regions. The 78 pairs appeared to be divided into two less definitive groups: those between and

256 those within continents (distances greater than and less than $4500 \mathrm{~km}$, respectively). When the

257 data were divided in that way, the relation of similarity to distance was much stronger between

258 than within continents (Figure 3,c-h). The vascular species in Europe still had a weak

259 relationship, but the European bryophytes and both vascular plants and bryophytes in North

260 America had no significant relations with distance (Figure 3,e-h); however, some $\mathrm{R}^{2}$ were

261 relatively high and the possibility of a relationship exists. Also, although several regressions

262 were significant, the plots revealed triangular patterns wherein the full range of similarities

263 occurred at the shortest distances with less similarity at the longest. These observations match

264 our first and second expectations.

265 The patterns differed between the vascular and bryophyte species. The triangular

266 relationship is more distinct, as indicated by the exponential relationship, for the vascular

267 species. The vascular similarity is higher at the shorter distances, specifically for oroarctic pairs,

268 while it has a tighter distribution at the longest distance. This geographic effect is also seen in the

269 difference in similarity between the vascular and bryophyte species: the greatest vascular minus

270 bryophyte differences are SOS versus SCT and NOS (0.0497 and 0.0281, respectively) while

271 CBR versus SCT and SOS (-0.0220 and -0.0179) are among the greatest bryophyte>vascular

272 differences (Table 6). These observations meet our second and third expectations.

\section{Ordination and General Linear Models}

274 In addition to stress (vascular, 21.9; bryophyte, 23.1), we examined the competence of

275 the NMDS ordination by correlating the distances between all pairs in ordination space with the

276 similarity matrix reduced by that ordination, increasing the number of axes until the increment in 
$277 \mathrm{r}$ was less than 0.05 . This method produced ordinations for both vascular and bryophyte groups

278 with four axes, with correlations with the similarity matrix of 0.444 and 0.452 , for vascular and

279 bryophytes respectively ( $\mathrm{p}<0.001$ for both).

280 The visualization of the ordination showed that the plots within each region were

281 clustered together: mid-latitude European plots are neighbors, mid-latitude North American plots

282 are neighbors, and the oroarctic plots are neighbors that separate the mid-continental European

283 and North American plots (Figure 4).

284 The GLMs revealed significant relationships for the mean positions of the 13 regions on

285 all four ordination axes for the vascular plant data, and on two of the four for the bryophyte data

286 (Table 7). For vascular species, the geographic factors of regionalization and distance were

287 important for all four axes, and geography accounted for more than double the variance in the

288 combined four ordination axes than the climatic variables. Of the latter, precipitation accounted

289 for almost all the contribution. For the bryophytes, overall GLMs were weaker, with no

290 significant variables for two of the four axes. Climate accounted for $44 \%$ of the contribution of

291 geography, with wet quarter precipitation the only significant climatic variables. For bryophytes,

292 the strongest individual relationship was for latitude, i.e., either mid-latitude or oroarctic, and

293 NMDS3 (74.7\% contribution). These observations meet all four of our expectations.

295 Discussion

296 Large-scale, biogeographic elevational and latitudinal patterns in mountain vegetation

297 have previously been thought to be primarily driven by climate (with the temporal change in

298 species distributions also associated with climatic changes). Our analyses tackled this question

299 and provide new evidence that location can supersede climate in the determination of large-scale 
300 biogeographic patterns in mountain species assemblages. First, distance is a consistent factor in

301 the differentiation of these assemblages or floras. Second, geographic regions are differentiated.

302 Distance matters primarily between rather than within continents. The relative importance of

303 distance, as seen in the patterns of similarity, in accounting for the variance in observed patterns

304 of beta diversity is indicative of processes at larger spatial and temporal scales. The triangular

305 patterns indicate that multiple factors may operate at smaller scales while geographic connection

306 through dispersal is the dominant process at larger scales. The triangular pattern is more evident

307 for vascular species because the similarity is higher at shorter distances, specifically for oroarctic

308 pairs, while it has a tighter distribution at the longest distances. Evolutionary differentiation of

309 floras and disequilibrium of communities in flux following Holocene climate changes would

310 weaken the link between current climates and similarity and reflect past connections through

311 dispersal. If these links are true, our results support the contention of McGill (2010) that

312 dispersal supersedes climate in determining community differentiation at the largest spatial

313 scales.

314 The distance-similarity and climatic relations differed between vascular plants and

315 bryophytes, with greater uncertainty in the latter. The findings qualitatively agree with the

316 findings of Nekola and White (1999), who found that vascular plants had 1.5-1.9 times higher

317 distance decay rates than bryophytes. Our results rather suggest that at hemispheric-

318 intercontinental scales, the difference is typically at least two times higher. The reasons for lower

319 similarity decay rates of bryophytes may be due to their longer evolutionary history and thus

320 generally wide geographic ranges, species persistence in microsites due to broad physiological

321 tolerances, or high migration rates. For example, Ledent et al. (2019) reported that the role of 
322 extra-continental migrants in European bryophyte community assembly since the LGM greatly

323 exceeded that of other plants.

324 Our results further indicate a novel pattern in that the difference in the decay rate between

325 vascular plants and bryophytes is geographically dependent. At intercontinental scale both

326 vascular plants and bryophytes show a decay in similarity, but at the continental scale, bryophyte

327 decay rates, in contrast to those for vascular species, are not significant in Europe, where our

328 eight ranges are less isolated than the five in North America. The pattern may reflect the minimal

329 dispersal limitation at these scales (too few points for North America prohibit inference) and the

330 differentiation of bryophytes between the mid-latitude and oroarctic latitudes regardless of

331 distance. Moreover, Lenoir et al. (2012) reported that the similarity decay rate of vascular plants

332 was about two times greater than that of bryophytes across a $4500 \mathrm{~km}$ gradient of high latitude

333 tundra, but for our four oroarctic regions (with only six points) the decay rate is two orders of

334 magnitude greater for vascular plants. This geographic effect is also seen in the difference in

335 similarity between the vascular and bryophyte species: the greatest vascular-minus-bryophyte

336 differences are SOS versus SCT and NOS (0.0497 and 0.0281, respectively) while CBR versus

337 SCT and SOS (-0.0220 and -0.0179) are among the greatest bryophyte>vascular differences.

338 Isolation is more than simple distance.

339 Whereas Virtanen et al. (2016) thought that the differences between the oroarctic and

340 mid-latitude tundra in Europe were in part attributable to climate and perhaps to differences in

341 relief, our addition of Scottish and Alaskan oroarctic regions provides additional insight. While

342 distance alone matters, the oroarctic connection between Europe and Alaska indicates that the

343 relationship to the circumarctic low elevation tundra may play a role in the similarity among

344 oroarctic regions. Also, the central Brooks Range has rugged topography like that of the Rocky 
345 Mountains or the Alps, but this region is not strongly differentiated from the other, less rugged,

346 oroarctic regions, suggesting that complexity of relief is probably less important in

347 differentiating mountain tundra. Cooper (1989) suggested that high elevation tundra in Alaska is

348 a good analog for widespread Beringian tundra of the Last Glacial Maximum, which accords

349 with this conclusion.

350 Among the climatic factors, differences in precipitation explained much of the pattern of 351 relations among both the vascular and bryophyte communities. Precipitation might be expected

352 to be a stronger factor than temperature, given the narrow range of the latter that defines

353 mountain tundra, and this finding complements the finding of Kikvidze et al. (2005) that

354 precipitation had the greater direct influence on alpha diversity in a global comparison. The

355 weaker climatic relations of the bryophytes echo the observations of Lang et al. (2012) for arctic

356 tundra. The bryophytes tend to be restricted to wetter sites, which minimizes the effects of

357 variation in regional precipitation.

358 Another specific geographic comparison can be made between the Mediterranean-climate 359 regions of California and Spain (the YNP and BET regions). These two have the lowest warm-

360 season precipitation, yet they are the most dissimilar pair. They are both toward the southwestern

361 extremes of their continents and have no mountain ranges farther in that direction (although

362 some connections to the Atlas Mountains may exist for BET and to the Sierra Madre for YNP).

363 Thus they are relatively isolated in both climate and geographic space. Both ranges are relatively

364 high in endemic species (Faverger 1972, Malanson, Zimmerman and Fagre 2015). For BET this

365 is probably because of its isolation but for the Sierra Nevada of California it may also be

366 attributable to its large area. 
Patterns of vegetation change observed in relation to past or present climate change

368 should be interpreted in light of regional and specific characteristics of place. Similar degrees of

369 change in the oroarctic and mid-latitude alpine tundra vegetation may signify different impacts,

370 given differences in functional types and responses to climate (Bruun et al. 2006). These

371 differences might even extend to greater geographic specificity, as where Lesica and McCune

372 (2004) have pointed out changes for arctic-centered species at their southern range limit in

373 Glacier National Park, Montana. Changes in locations with more endemic species, e.g., in BET,

374 should perhaps be weighted more in terms of impact assessment.

375 Mountain tundra is undergoing changes that could threaten its unique character (e.g.,

376 Britton et al. 2009). It is also potentially threatened by rising treelines in some areas and by

377 rising low-elevation arctic tundra in others (e.g., Vanneste et al. 2017). Controversial ideas about

378 mitigation include assisted migration - moving plants poleward to track their geographically

379 shifting climatic niche (e.g., Abeli et al. 2014, Ramírez-Amezcua et al. 2016, Pykälä 2017). For

380 the mountain tundra examined here, this idea must face simple problems of uncertainty before

381 the complex ones related to ethics. Brooker et al. (2018) have shown that it may be particularly

382 difficult to translocate some mountain tundra species because of our inadequate knowledge of

383 their niche and the difficulty of identifying climatically-suitable locations within topographically

384 complex mountain landscapes. At larger scales, mountain tundra is already near the end of the

385 global temperature gradient. Little area exists where it is now too cold for tundra plants but

386 where substrates exist to support any in a warmer future. Retreating glaciers would nominally

387 provide space, but the threshold switch from ice to ice-free may not leave the needed range of

388 temperature in its wake. Additionally, the rate of warming is expected to be greater at higher

389 latitudes (Serreze et al. 2000), further limiting the feasibility of poleward migration. Even within 
ranges, elevation-dependent warming (Rangwala and Miller 2012) will limit the amount of new

391 area to which alpine plants could migrate (with or without assistance). Given that mountain

392 tundra does not align on simple climatic gradients, it is not clear that any region could or should

393 be a target for translocations from any other. When considering assisted migration of mid-

394 latitude tundra species, the oroarctic regions may already be too threatened to serve as a suitable

395 receptor region. Given its distinct floristic character and that oroarctic tundra is faced with the

396 potential for greater warming, less active mitigation and more protection (e.g., Thuiller et al.

397 2014) may be a better strategy.

398

399 Conclusions

$400 \quad$ Fundamental theory in biogeography is based on changes in scale, and disentangling the

401 roles of abiotic, biotic, and dispersal drivers as they vary with scale continues to be a frontier of

402 research. For hemispheric patterns of mountain tundra, the effects of climatic differences are

403 superseded by those of geographic distance at the most extensive scale, as examined here for the

404 first time. More quantification of the form of the transitions among drivers along a gradient of

405 scale is needed, however, with attention to smaller scales where local habitat factors are likely to

406 be important. The specifics of geography, such as isolation, also matter - as well-known since

407 Darwin and Wallace.

408 The relevance of biogeographic theory to the conservation in a changing climate is also

409 dependent on the details of biogeography, such as latitudinal gradients, as well as on scale. Given

410 the potential problems that global climate change poses for mountain tundra, approaches to

411 mitigation should be considered. Although biogeographic theory is relevant to all five of the

412 approaches categorized by Malanson et al. (2019), the patterns revealed here further limit the 
413 efficacy of the most fraught approach, assisted migration. When the implications of local context

414 and scale are recognized, the balance among mitigation choices may shift. 


\section{References}

416 Abeli, T., S.E. Dalrymple, A. Mondoni, S. Orsenigo, and G. Rossi. 2014. Integrating a

417 biogeographical approach into assisted colonization activities is urgently needed. Plant

418 Biosystems 148 (6):1355-1357.

419 Anthelme, F., D. Jacobsen, P. Macek, R.I. Meneses, P. Moret, S. Beck, and O. Dangles. 2014.

420 Biodiversity patterns and continental insularity in the tropical High Andes. Arctic, Antarctic, and 421 Alpine Research 46 (4):811-828.

422 Archer, A.C. 1963. Some synecological problems in the alpine zone of Garibaldi Park. MS

423 thesis, University of British Columbia, Vancouver.

424 Austin, M.P. 2013. Inconsistencies between theory andmethodology: a recurrent problemin 425 ordination studies. Journal of Vegetation Science 24: 251-268.

426 Averis, A.B. Averis, J. Birks, D. Horsfield, D. Thompson, and M. Yeo. 2004. An illustrated

427 guide to British upland vegetation. Peterborough, UK: Joint Nature Conservation Committee.

428 Berry, K.J., K.L. Kvamme, and P.W. Mielke. 1983. Improvements in the permutation test for the 429 spatial analysis of the distribution of artifacts into classes. American Antiquity 48 (3):547-553.

430 Bhatta, K.P., J-A. Grytnes, and O.R. Vetaas. 2018. Scale sensitivity of the relationship between 431 alpha and gamma diversity along an alpine elevation gradient in central Nepal. Journal of

432 Biogeography 45 (4):804-814

433 Billings, W.D. 1973. Arctic and alpine vegetations: similarities, differences, and susceptibility to 434 disturbance. BioScience 23 (12):697-704.

435 Birse, E.L. 1976. The bioclimate of Scotland in relation to a world system of classification and to 436 land use capability. Transactions of the Botanical Society of Edinburgh 42 (4):463-467. 
437 Birse, E.L. 1980. Plant communities of Scotland: revised and additional tables. A preliminary

438 phytocoenonia. Aberdeen: Macaulay Institute for Soil Research.

439 Braun-Blanquet, J. 1926. Vegetations-Entwicklung und Bodenbildung in der alpinen Stufe der

440 Zentralpen, under mitwirkung von Hans Jenny. Zürich: Fretz.

441 Braun-Blanquet, J. 1948. La végétation alpine des Pyrénées Orientales. Monografías de la

442 Estación de Estudios Pirenaicos y del Instituto Español de Edafología, Ecología y Fisiología

443 Vegetal 9 (Bot. 1):1-306.

444 Brett, R.B., K. Klinka, and H. Qian. 2001. Classification of high-elevation non-forested plant

445 communities in coastal British Columbia. Scientia Silvica Extension Series 29. Vancouver:

446 University of British Columbia.

447 Britton, A.J., C.M. Beale, W. Towers, and R. L. Hewison. 2009. Biodiversity gains and losses:

448 evidence for homogenisation of Scottish alpine vegetation. Biological Conservation 142

449 (8):1728-1739.

450 Brooker, R.W., M.J. Brewer, A.J. Britton, A. Eastwood, C. Ellis, A. Gimona, L. Poggio, and

451 D.R. Genney. 2018. Tiny niches and translocations: The challenge of identifying suitable

452 recipient sites for small and immobile species. Journal of Applied Ecology 55 (2):621-630.

453 Bruun, H.H., R. Virtanen, J.A. Grytnes, L. Oksanen, and A. Angerbjorn. 2006. Effects of altitude

454 and topography on species richness of vascular plants, bryophytes and lichens in alpine

455 communities. Journal of Vegetation Science 17 (1):37-46.

456 Chalmandrier, L., T. Münkemüller, M.P. Colace, J. Renaud, S. Aubert, B.Z. Carlson, J.C.

457 Clément, N. Legay, G. Pellet, A. Saillard, and S. Lavergne. 2017. Spatial scale and intraspecific

458 trait variability mediate assembly rules in alpine grasslands. Journal of Ecology 105 (1):277-287. 
459 Clarke, A.G., J.M. Lord, X.B. Hua, and R. Ohlemuller. 2018. Does current climate explain plant 460 disjunctions? A test using the New Zealand alpine flora. Journal of Biogeography 45 (7):1490$461 \quad 1499$.

462 Cooper, D.J. 1989. Geographical and ecological relationships of the arctic-alpine vascular flora 463 and vegetation, Arrigetch Peaks region, central Brooks Range, Alaska. Journal of Biogeography $46416(3): 279-295$.

465 D'Amen, M., H.K., Mod, N.J. Gotelli, and A. Guisan. 2018. Disentangling biotic interactions, 466 environmental filters, and dispersal limitation as drivers of species co-occurrence. Ecography 41 467 (8):1233-1244.

468 Damm, C. 2001. A phytosociological study of Glacier National Park, Montana, USA, with notes 469 on the syntaxonomy of alpine vegetation in western North America. PhD diss., Georg-August $470 \quad$ Universitaet, Germany.

471 Douda, J., A. Havrdova, J. Doudova, and B. Mandak. 2018. Legacy of post-glacial colonization 472 affects ß-diversity: Insights into local community assembly processes. Journal of Biogeography $47345(7): 1604-1615$.

474 Draper, N.R. and H. Smith. 2014. Applied regression analysis, $3^{\text {rd }}$ ed. New York: Wiley.

475 Elmendorf, S.C., G.H. Henry, R.D. Hollister, R.G. Björk, A.D. Bjorkman, T.V. Callaghan, L.S. 476 Collier, E.J. ,Cooper, J.H. Cornelissen, T.A. Day, and A.M. Fosaa. 2012. Global assessment of 477 experimental climate warming on tundra vegetation: heterogeneity over space and time. Ecology 478 Letters 15 (2):164-175.

479 Faverger, C. 1972. Endemism in the montane floras of Europe. In Taxonomy, phytogeography 480 and evolution, ed. D.H. Valentine, 191-204, London: Academic Press. 
481 Ferrarini, A.J., M. Alatalo, D. Gervasoni, and B. Foggi. 2017. Exploring the compass of potential 482 changes induced by climate warming in plant communities. Ecological Complexity 29 (1):1-9. 483 Fick, S.E., and R.J. Hijmans. 2017. WorldClim 2: new 1-km spatial resolution climate surfaces 484 for global land areas. International Journal of Climatology 37 (12):4302-4315.

485 García-Gutiérrez, T., B. Jiménez-Alfaro, E. Fernández-Pascual, and J.V. Müller. 2018.

486 Functional diversity and ecological requirements of alpine vegetation types in a biogeographical 487 transition zone. Phytocoenologia $48(1): 77-89$.

488 García-Porta, J., M. Simo-Riudalbas, M. Robinson, and S. Carranza. 2017. Diversification in arid 489 mountains: biogeography and cryptic diversity of Pristurus rupestris rupestris in Arabia. Journal 490 of Biogeography $44(8): 1694-1704$.

491 Gritsch, A., T. Dirnböck, and S. Dullinger. 2016. Recent changes in alpine vegetation differ 492 among plant communities. Journal of Vegetation Science 27 (6):1177-1186.

493 Hadley, K.S. 1987. Vascular alpine plant distributions within the central and southern Rocky 494 Mountains, USA. Arctic and Alpine Research 19 (3):242-251.

495 Harbert, B.L., and D.J. Cooper. 2017. Environmental drivers of subalpine and alpine fen 496 vegetation in the Southern Rocky Mountains, Colorado, USA. Plant Ecology 218 (7):885-898.

497 Harris, S.A. 2007. Biodiversity of the alpine vascular flora of the NW North American

498 cordillera: the evidence from phyto-geography. Erdkunde 61 (4):344-357

499 Hewitt, G.M. 1996. Some genetic consequences of ice ages, and their role in divergence and 500 speciation. Biological Journal of the Linnean Society 58 (3):247-276.

501 Hewitt, N., N. Klenk, A.L. Smith, D.R. Bazely, N. Yan, S. Wood, J.I. MacLellan, C. Lipsig502 Mumme, and I. Henriques. 2011. Taking stock of the assisted migration debate. Biological 503 Conservation $144(11): 2560-2572$. 
504 Hoorn, C., V. Mosbrugger, A. Mulch, and A. Antonelli. 2013. Biodiversity from mountain

505 building. Nature Geoscience 6 (3): 154.

506 Jiménez-Alfaro, B., S. Suárez-Seoane, M. Chytrý, S.M. Hennekens, W. Willner, M. Hájek E.

507 Agrillo, JM. Álvarez-Martínez, A. Bergamini, H. Brisse, and J. Brunet. 2018. Modelling the

508 distribution and compositional variation of plant communities at the continental scale. Diversity

509 and Distributions 24 (7):978-990.

510 Kammer, P.M., C. Schöb, and P. Choler. 2007. Increasing species richness on mountain

511 summits: Upward migration due to anthropogenic climate change or re-colonisation? Journal of

512 Vegetation Science 18 (2):301-306.

513 Karger, D.N., Conrad, O., Böhner, J., Kawohl, T., Kreft, H., Soria-Auza, R.W., Zimmermann,

514 N.E., Linder, H.P. and Kessler, M., 2017. Climatologies at high resolution for the earth's land

515 surface areas. Scientific Data 4:170122.

516 Kikvidze, Z., F.I. Pugnaire, R.W. Brooker, P. Choler, C.J. Lortie, R. Michalet, and Callaway,

517 R.M. 2005. Linking patterns and processes in alpine plant communities: A global study. Ecology

$518 \quad 86(6): 1395-1400$.

519 Kim, D., D.M. Cairns, J. Bartholdy, and C.L. Morgan. 2012. Scale-dependent correspondence of

520 floristic and edaphic gradients across salt marsh creeks. Annals of the Association of American

521 Geographers $102(2): 276-294$.

522 Komarkova, V. 1979. Alpine vegetation of the Indian Peaks Area. Vaduz, Liechtenstein: J

523 Cramer.

524 Körner, C. 2000. Why are there global gradients in species richness? Mountains might hold the 525 answer. Trends in Ecology and Evolution 15 (12):513-514. 
526 Lang, S.I., Cornelissen, J.H., Shaver, G.R., Ahrens, M., Callaghan, T.V., Molau, U., Ter Braak,

527 C.J., Hölzer, A. and Aerts, R. 2012. Arctic warming on two continents has consistent negative 528 effects on lichen diversity and mixed effects on bryophyte diversity. Global Change Biology 18 529 (3):1096-1107.

530 Ledent, A., A. Désamoré, B. Laenen, P. Mardulyn, S.F. McDaniel, F. Zanatta, J. Patiño, and A.

531 Vanderpoorten. 2019. No borders during the post-glacial assembly of European bryophytes.

532 Ecology Letters 22 (6): 973-986.

533 Legendre, P., M. J. Fortin, and D. Borcard. 2015. Should the Mantel test be used in spatial 534 analysis? Methods in Ecology and Evolution 6 (11):1239-1247.

535 Lenoir, J., Virtanen, R., Oksanen, J., Oksanen, L., Luoto, M., Grytnes, J. A., \& Svenning, J. C.

536 (2012). Dispersal ability links to cross-scale species diversity patterns across the Eurasian Arctic

537 tundra. Global Ecology and Biogeography 21 (8):851-860.

538 Lesica, P., and B. McCune, 2004. Decline of arctic-alpine plants at the southern margin of their 539 range following a decade of climatic warming. Journal of Vegetation Science 15 (5):679-690.

540 Lesica, P., and E.E. Crone. 2017. Arctic and boreal plant species decline at their southern range 541 limits in the Rocky Mountains. Ecology Letters 20 (2):166-174.

542 Li, Q., X. Yang, J. Soininen, C.J. Chu, J.Q. Zhang, K.L Yu, and G. Wang. 2011. Relative

543 importance of spatial processes and environmental factors in shaping alpine meadow

544 communities. Journal of Plant Ecology 4 (4):249-258.

545 Löffler, J., and R. Pape. 2008. Diversity patterns in relation to the environment in alpine tundra 546 ecosystems of northern Norway. Arctic, Antarctic, and Alpine Research 40 (2):373-381.

547 Malanson, G.P., A.B. Cheney, and M. Kinney. 2015. Climatic and geographic relations of alpine 548 tundra floras in western North America. Alpine Botany 125 (1):21-29. 
549 Malanson, G.P., D.L. Zimmerman, and D.B. Fagre. 2015. Floristic similarity, diversity, and

550 endemism as indicators of refugia characteristics and needs in the West. Biodiversity 16 (4):237-

551246.

552 Malanson, G.P., D.L. Zimmerman, M. Kinney, and D.B. Fagre. 2017. Relations of alpine plant

553 communities across environmental gradients: Multilevel versus multiscale analyses. Annals of

554 the American Association of Geographers 107 (1):41-53.

555 Malanson, G.P., D.B. Fagre, and D.L. Zimmerman. 2018. Scale dependence of diversity in

556 alpine tundra, Rocky Mountains, USA. Plant Ecology 219 (8):999-1008.

557 Malanson, G.P., L.M. Resler, D.R. Butler, and D.B. Fagre. 2019. Mountain plant communities:

558 Uncertain sentinels? Progress in Physical Geography 43 (4): 521-543.

559 Mantel, N. 1967. The detection of disease clustering and a generalized regression approach.

560 Cancer Research 27 (2,Part 1):209-220.

561 McCune, B., and J.B. Grace. 2002. Analysis of ecological communities. Gleneden Beach, OR:

562 MjM Software Design.

563 McGill, B.J. 2010. Matters of scale. Science 328 (5978):575-576.

564 Meentemeyer, V. 1989. Geographical perspectives of space, time, and scale. Landscape Ecology $565 \quad 3: 163-173$.

566 Molau, U. and J.M. Alatalo. 1998. Responses of subarctic-alpine plant communities to simulated

567 environmental change: biodiversity of bryophytes, lichens, and vascular plants. Ambio 27

568 (4):322-329.

569 Muster, C., W.P. Maddison, S. Uhlmann, T.U. Berendonk, and A.P. Vogler. 2009. Arctic-alpine

570 distributions - metapopulations on a continental scale? American Naturalist 173 (3):313-326. 
571 Nekola, J. C., \& White, P. S. (1999). The distance decay of similarity in biogeography and

572 ecology. Journal of Biogeography, 26 (4), 867-878.

573 Opedal ØH, W.S. Armbruster, B.J. Graae. 2015. Linking small-scale topography with

574 microclimate, plant species diversity and intra-specific trait variation in an alpine landscape.

575 Plant Ecology and Diversity 8 (3):305-315.

576 Patsiou, T.S., E. Conti, N.E. Zimmermann, S. Theodoridis, and C.F. Randin. 2014. Topo-

577 climatic microrefugia explain the persistence of a rare endemic plant in the Alps during the last

57821 millennia. Global Change Biology 20 (7):2286-2300.

579 Pemble, R.H. 1970. Alpine vegetation in the Sierra Nevada of California as lithosequences and

580 in relation to local site factors. PhD Diss., University of California, Davis.

581 Peres-Neto, P.R., and P. Legendre. 2010. Estimating and controlling for spatial structure in the

582 study of ecological communities. Global Ecology and Biogeography 19 (2):174-184.

583 Petraglia, A., and M. Tomaselli. 2007. Phytosociological study of the snowbed vegetation in the

584 Northern Apennines (Northern Italy. Phytocoenologia 37 (1):67-98.

585 Pykälä, J. 2017. Relation between extinction and assisted colonization of plants in the arctic-

586 alpine and boreal regions. Conservation Biology 31 (3):524-530.

587 Ramírez-Amezcua, Y., V.W. Steinmann, E. Ruiz-Sanchez, and O.R. Rojas-Soto. 2016. Mexican

588 alpine plants in the face of global warming: potential extinction within a specialized assemblage

589 of narrow endemics. Biodiversity and Conservation 25 (5):865-885.

590 Rangwala, I., and J.R. Miller. 2012. Climate change in mountains: a review of elevation-

591 dependent warming and its possible causes. Climatic Change 114 (3-4):527-547.

592 Riebesell, J.F. 1982. Arctic-alpine plants on mountain tops: agreement with island biogeography 593 theory. American Naturalist 119 (5):657-674. 
594 Serreze, M., J. Walsh, F.S. Chapin, T. Osterkamp, M. Dyurgerov, V. Romanovsky, W. Oechel, J.

595 Morison, T. Zhang, and R. Barry. 2000. Observational evidence of recent change in the northern

596 high-latitude environment. Climatic Change 46 (1-2):159-207.

597 Smycka, J., C. Roquet, J. Renaud, W. Thuiller, N.E. Zimmermann, and S. Lavergne. 2017.

598 Disentangling drivers of plant endemism and diversification in the European Alps - A

599 phylogenetic and spatially explicit approach. Perspectives in Plant Ecology, Evolution and

600 Systematics 28:19-27.

601 Socolar, J.B., J.J. Gilroy, W.E. Kunin, and D.P. Edwards. 2016. How should beta-diversity

602 inform biodiversity conservation? Trends in Ecology and Evolution 31 (1):67-80.

603 Sørenson, T. 1948. A method of establishing groups of equal amplitudes in plant sociology based

604 on similarity of species content and its application to analyses of the vegetation on Danish

605 commons. Kongelige Danske Videnskabernes Selskab, Biologiske Skrifter 5:1-34.

606 Spasojevic, M.J., W.D. Bowman, H.C. Humphries, T.R. Seastedt, K.N. Suding. 2013. Changes

607 in alpine vegetation over 21 years: Are patterns across a heterogeneous landscape consistent with

608 predictions? Ecosphere 4:\#117.

609 Steinbauer, M.J., J.A. Grytnes, G. Jurasinski, A. Kulonen, J. Lenoir, H. Pauli, C. Rixen, M.

610 Winkler, M. Bardy-Durchhalter, E. Barni, and A.D. Bjorkman. 2018. Accelerated increase in

611 plant species richness on mountain summits is linked to warming. Nature 556 (7700):231-234.

612 Stivrins N, J. Soininen, L. Amon, S.L. Fontana, G. Gryguc, M. Heikkilä, O. Heiri, D. Kisielienè,

613 T. Reitalu, M. Stančikaitè, and S. Veski. 2016. Biotic turnover rates during the Pleistocene-

614 Holocene transition. Quaternary Science Reviews 151:100-110. 
615 Suding, K.N., E.C. Farrer, A.J. King, L. Kueppers, and M.J. Spasojevic. 2015. Vegetation

616 change at high elevation: scale dependence and interactive effects on Niwot Ridge. Plant

617 Ecology and Diversity 8 (5-6):713-725.

618 Taylor, D.W. 1977. Floristic relationships along the Cascade-Sierran axis. American Midland

619 Naturalist 97 (2):333-349.

620 Thuiller, W., Guéguen, M., Georges, D., Bonet, R., Chalmandrier, L., Garraud, L., Renaud, J.,

621 Roquet, C., Van Es, J., Zimmermann, N.E. and Lavergne, S., 2014. Are different facets of plant

622 diversity well protected against climate and land cover changes? A test study in the French Alps.

623 Ecography, 37 (12), pp.1254-1266.

624 Vanneste, T., O. Michelsen, B.J. Graae, M.O. Kyrkjeeide, H. Holien, K. Hassel, S. Lindmo, R.E

625 Kapás, and P. De Frenne. 2017. Impact of climate change on alpine vegetation of mountain

626 summits in Norway. Ecological Research 32 (4):579-593.

627 Virtanen, R., and S. Eurola. 1997. Middle oroarctic vegetation in Finland and middle-northern

628 arctic vegetation on Svalbard. Acta Phytogeographica Suecica 82. Uppsala: Opulus Press.

629 Virtanen, R., L. Oksanen, T. Oksanen, J. Cohen, B.C. Forbes, B. Johansen, J. Käyhkö, J.

630 Olofsson, J. Pulliainen, and H. Tømmervik. 2016. Where do the treeless tundra areas of northern

631 highlands fit in the global biome system: toward an ecologically natural subdivision of the tundra

632 biome. Ecology and Evolution 6 (1):143-158.

633 Von Humboldt, A. and A. Bonpland. 1805. Essais sur le geographie des plantes. Paris: Chez

634 Levrault, Schoell et Compagnie.

635 Vuorinen, K.E., L. Oksanen, T. Oksanen, A. Pyykönen, J. Olofsson, and R. Virtanen. 2017.

636 Open tundra persist, but arctic features decline-Vegetation changes in the warming

637 Fennoscandian tundra. Global Change Biology 23 (9):3794-3807. 
638 Walker, M.D., C.H. Wahren, R.D. Hollister, G.H. Henry, L.E. Ahlquist, J.M. Alatalo, M.S. Bret-

639 Harte, M.P. Calef, T.V. Callaghan, A.B. Carroll, and H.E. Epstein. 2006. Plant community

640 responses to experimental warming across the tundra biome. Proceedings of the National

641 Academy of Sciences 103 (5):1342-1346.

642 Walsh S.J., D.R. Butler, and G.P. Malanson. 1997. An overview of scale, pattern, process

643 relationships in geomorphology: a remote sensing and GIS perspective. Geomorphology 21: 183-

644205.

645 Wolfe, J.A. 1987. An overview of the origins of the modern vegetation and flora of the northern

646 Rocky Mountains. Annals of the Missouri Botanical Garden 74 (4):785-803.

647 
6481e 1. The regions used, showing the codes referred to in the text, their central locations and elevations, general 64hate type, relative relief, and the number of plots in the original data, and the reduced number used in the 65leulations.

\begin{tabular}{|c|c|c|c|c|c|c|c|}
\hline 65de & Latitude & Longitude & Elevation (m) & Climate & initial\# & \#used-v & \#used-b \\
\hline AI2P & $46.62 \mathrm{~N}$ & $8.41 \mathrm{E}$ & 2950 & continental & 167 & 167 & 94 \\
\hline BEST & $37.05 \mathrm{~N}$ & $3.37 \mathrm{~W}$ & 3200 & Mediterranean low & 347 & 200 & $\mathrm{n} / \mathrm{a}$ \\
\hline $654 \mathrm{~N}$ & $43.19 \mathrm{~N}$ & $4.96 \mathrm{~W}$ & 2100 & maritime & 577 & 200 & $\mathrm{n} / \mathrm{a}$ \\
\hline 6SBR & $69.28 \mathrm{~N}$ & $143.82 \mathrm{~W}$ & 2200 & continental & 438 & 200 & 200 \\
\hline 618 & $48.72 \mathrm{~N}$ & $113.63 \mathrm{~W}$ & 2400 & continental & 525 & 200 & 200 \\
\hline EBA & $40.06 \mathrm{~N}$ & $105.59 \mathrm{~W}$ & 3600 & continental & 481 & 200 & 200 \\
\hline $658 \mathrm{P}$ & $44.25 \mathrm{~N}$ & $10.41 \mathrm{E}$ & 2000 & Mediterranean low & 305 & 200 & 200 \\
\hline 609 & $69.04 \mathrm{~N}$ & $20.86 \mathrm{E}$ & 1000 & maritime & 235 & 200 & 200 \\
\hline BAOR & $42.41 \mathrm{~N}$ & $2.21 \mathrm{E}$ & 2650 & Mediterranean high & 340 & 200 & 146 \\
\hline SBC & $50.11 \mathrm{~N}$ & $123.22 \mathrm{~W}$ & 2000 & maritime & 152 & 151 & 128 \\
\hline 6621 & $57.07 \mathrm{~N}$ & $3.67 \mathrm{~W}$ & 1300 & maritime & 540 & 200 & 200 \\
\hline SQS & $61.66 \mathrm{~N}$ & $7.02 \mathrm{E}$ & 1900 & maritime & 368 & 200 & 200 \\
\hline 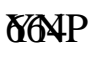 & $37.96 \mathrm{~N}$ & $119.32 \mathrm{~W}$ & 3650 & Mediterranean high & 188 & 188 & $\mathrm{n} / \mathrm{a}$ \\
\hline
\end{tabular}

6. 566in, EuroVeg.org; CAN, Cantabrian Range, Spain, EuroVeg.org; CBR central Brooks Range, Alaska, Arctic \$6egetation Archive (geobotany.uaf.edu); GNP, Glacier National Park, Montana, Damm (2001); IPA, Indian Peaks A68a, Colorado, Komarkova (1979); NAP, Northern Apennines, Italy, Petraglia \& Tomaselli (2007); NOS, northern 669ndinavia, Norway, EuroVeg.org; PYR, eastern Pyrenees, Spain, France, Andorra, Braun-Blanquet (1948); SBC, so0thern British Columbia, Archer (1963), Brett, Klinka and Qian (2001); SCT, Scotland, Birse (1976, 1980); SOS, 6outhern Scandinavia, Norway, EuroVeg.org; YNP, Yosemite vicinity, Sierra Nevada, California, Pemble (1970).

672

673 
674 Table 2. The climate variables used; Annual; Warm - warmest quarter; Cold - coldest quarter;

675 Wet - wettest quarter; Dry - driest quarter; $\mathrm{T}$ - mean temperature $\left({ }^{\circ} \mathrm{C}\right) ; \mathrm{P}$ - mean precipitation

$676(\mathrm{~mm})$. Data for three points in each region were drawn from the CHELSA downscaled product.

\begin{tabular}{|c|c|c|c|c|c|c|c|c|}
\hline Region & $\begin{array}{l}\text { AnnualT } \\
\left({ }^{\circ} \mathrm{C}\right)\end{array}$ & $\begin{array}{l}\text { WarmT } \\
\left({ }^{\circ} \mathrm{C}\right)\end{array}$ & $\begin{array}{l}\text { ColdT } \\
\left({ }^{\circ} \mathrm{C}\right)\end{array}$ & $\begin{array}{l}\text { AnnualP } \\
(\mathrm{mm})\end{array}$ & $\begin{array}{l}\text { WetP } \\
(\mathrm{mm})\end{array}$ & $\begin{array}{l}\text { DryP } \\
(\mathrm{mm})\end{array}$ & $\begin{array}{l}\text { WarmP } \\
(\mathrm{mm})\end{array}$ & $\begin{array}{l}\text { ColdP } \\
(\mathrm{mm})\end{array}$ \\
\hline ALP & -2.8 & 6.2 & -11.3 & 979 & 389 & 143 & 389 & 160 \\
\hline BET & 1.4 & 10.8 & -5.3 & 591 & 248 & 17 & 17 & 232 \\
\hline CAN & 3.9 & 10.5 & -1.3 & 1584 & 583 & 185 & 185 & 345 \\
\hline CBR & -11.7 & 7.1 & -27.3 & 423 & 248 & 42 & 167 & 73 \\
\hline GNP & 0.5 & 11.9 & -9.6 & 952 & 325 & 159 & 169 & 251 \\
\hline IPA & -2.7 & 8.2 & -12.1 & 679 & 236 & 115 & 209 & 121 \\
\hline NAP & 2.8 & 12.4 & -5.6 & 1049 & 373 & 184 & 213 & 249 \\
\hline NOS & -2.0 & 8.5 & -11.6 & 727 & 246 & 105 & 194 & 203 \\
\hline PYR & 0.0 & 8.5 & -7.3 & 955 & 308 & 166 & 272 & 193 \\
\hline SBC & 0.6 & 9.5 & -7.8 & 2501 & 1161 & 201 & 202 & 1125 \\
\hline SCT & 3.6 & 9.3 & -1.4 & 1462 & 481 & 251 & 311 & 721 \\
\hline SOS & -2.7 & 7.1 & -11.5 & 974 & 333 & 158 & 332 & 236 \\
\hline YNP & 0.6 & 12.1 & -6.5 & 837 & 446 & 43 & 43 & 444 \\
\hline
\end{tabular}

677

678

679 
68able 3. The distances $(\mathrm{km})$ between pairs of regions, the single significant Moran 6 igenvector based on principle coordinates analysis of that matrix, the average distance 6 62all 12 other regions (Dist12, km), and the summed distance to the three nearest Grëighbors (Dist3, km).

\begin{tabular}{|c|c|c|c|c|c|c|c|c|c|c|c|c|}
\hline & ALP & BET & CAN & CBR & GNP & IPA & NAP & NOS & PYR & SBC & SCT & SOS \\
\hline ALP & 0 & 1439 & 1117 & 6913 & 8030 & 8371 & 306 & 2583 & 678 & 8285 & 1420 & 1674 \\
\hline BET & 1439 & 0 & 696 & 7765 & 8250 & 8335 & 1409 & 3851 & 762 & 8682 & 2228 & 2826 \\
\hline CAN & 1117 & 696 & 0 & 7068 & 7646 & 7809 & 1240 & 3236 & 590 & 8045 & 1547 & 2197 \\
\hline CBR & 6913 & 7765 & 7068 & 0 & 2805 & 3934 & 7222 & 4596 & 7284 & 2403 & 5609 & 5276 \\
\hline GNP & 8030 & 8250 & 7646 & 2805 & 0 & 1155 & 8332 & 6397 & 8085 & 709 & 6613 & 6646 \\
\hline IPA & 8371 & 8335 & 7809 & 3934 & 1155 & 0 & 8650 & 7105 & 8328 & 1767 & 6988 & 7200 \\
\hline NAP & 306 & 1409 & 1240 & 7222 & 8332 & 8650 & 0 & 2824 & 693 & 8616 & 1731 & 1949 \\
\hline NOS & 2583 & 3851 & 3236 & 4596 & 6397 & 7105 & 2824 & 0 & 3150 & 6452 & 1794 & 1037 \\
\hline PYR & 678 & 762 & 590 & 7284 & 8085 & 8328 & 693 & 3150 & 0 & 8438 & 1683 & 2159 \\
\hline SBC & 8285 & 8682 & 8045 & 2403 & 709 & 1767 & 8616 & 6452 & 8438 & 0 & 6884 & 6829 \\
\hline SCT & 1420 & 2228 & 1547 & 5609 & 6613 & 6988 & 1731 & 1794 & 1683 & 6884 & 0 & 791 \\
\hline SOS & 1674 & 2826 & 2197 & 5276 & 6646 & 7200 & 1949 & 1037 & 2159 & 6829 & 791 & 0 \\
\hline YNP & 9248 & 9409 & 8837 & 3783 & 1280 & 1206 & 9581 & 7685 & 9301 & 1385 & 7865 & 7939 \\
\hline Moran1 & -10204 & -9630 & -9431 & 9526 & 14082 & 14303 & -10420 & -4683 & -10303 & 14598 & -7410 & -6878 \\
\hline Dist12 & 4172 & 4638 & 4169 & 5388 & 5496 & 5904 & 4379 & 4226 & 4263 & 5708 & 3763 & 3877 \\
\hline $\begin{array}{l}\text { Dist3 } \\
684\end{array}$ & 700 & 956 & 801 & 2997 & 1048 & 1376 & 746 & 1805 & 654 & 1287 & 1253 & \\
\hline
\end{tabular}

685

686 
687 Table 4. Multiple Response Permutation Procedure (MRPP) effect size, A (chance-corrected 688 metric showing differences in comparisons). The comparison was between continents, latitudes, 689 and their combination; continents - Europe, EU, and North America, NA; latitudes - midlatitude, $690 \mathrm{ML}$, and oroarctic, OA. The separation between groups is significant in all comparisons with $p<$ 6910.000001.

692

Vascular A

Bryophyte A

6932 continents

0.010

0.011

6942 latitudes

0.013

0.013

695 Continent by latitudes

696

EU-ML vs. NA-ML

0.010

0.020

697

EU-ML vs. NA-OA

0.025

0.025

698

EU-ML vs. EU-OA

0.019

0.014

699

700

NA-ML vs. NA-OA

0.027

0.029

701

NA-ML vs. EU-OA

0.024

0.022

NA-OA vs. EU-OA

0.040

0.015

702

703

704 
705

706

707

708

709

710

711

Table 5. Mean Sørenson floristic similarity between regions for vascular species (upper triangular; 78 pairs) and bryophytes (lower triangle; 45 pairs); the diagonal is the within-region similarity calculated using both taxa (for YNP it is 0.540). The mean is from all possible pairs of plots between the pairs of regions. Sørenson similarity is the proportion of species abundance shared to the total abundance of each pair of plots. The similarities between regions are low, as are the within-region similarities.

\begin{tabular}{|c|c|c|c|c|c|c|c|c|c|c|c|}
\hline & ALP & BET & CAN & CBR & GNP & IPA & NAP & NOS & PYR & SBC & SCT \\
\hline ALP & 0.0821 & 0.0024 & 0.0098 & 0.0106 & 0.0059 & 0.0072 & 0.0187 & 0.0235 & 0.0163 & 0.0020 & 0.0087 \\
\hline BET & & 0.5963 & 0.0186 & 0.0014 & 0.0002 & 0.0002 & 0.0077 & 0.0005 & 0.0048 & 0.0005 & 0.0079 \\
\hline CAN & & & 0.7862 & 0.0016 & 0.0021 & 0.0010 & 0.0211 & 0.0056 & 0.0148 & 0.0002 & 0.0253 \\
\hline CBR & 0.0095 & & & 0.1414 & 0.0239 & 0.0106 & 0.0137 & 0.0357 & 0.0032 & 0.0017 & 0.0040 \\
\hline GNP & 0.0125 & & & 0.0039 & 0.0940 & 0.0131 & 0.0037 & 0.0096 & 0.0048 & 0.0088 & 0.0014 \\
\hline IPA & 0.0089 & & & 0.0029 & 0.0538 & 0.0221 & 0.0011 & 0.0066 & 0.0021 & 0.0033 & 0.0020 \\
\hline NAP & 0.0063 & & & 0.0180 & 0.0056 & 0.0066 & 0.1663 & 0.0151 & 0.0174 & 0.0039 & 0.0444 \\
\hline NOS & 0.0125 & & & 0.0248 & 0.0053 & 0.0073 & 0.0301 & 0.0926 & 0.0084 & 0.0024 & 0.0481 \\
\hline PYR & 0.0443 & & & 0.0083 & 0.0070 & 0.0124 & 0.0215 & 0.0226 & 0.0592 & 0.0016 & 0.0114 \\
\hline SBC & 0.0101 & & & 0.0047 & 0.0130 & 0.0164 & 0.0088 & 0.0104 & 0.0052 & 0.0669 & 0.0014 \\
\hline SCT & 0.0011 & & & 0.0231 & 0.0015 & 0.0021 & 0.0263 & 0.0263 & 0.0203 & 0.0072 & 0.1475 \\
\hline OS & 0.0081 & & & 0.0310 & 0.0045 & 0.0057 & 0.0268 & 0.0311 & 0.0225 & 0.0063 & 0.0299 \\
\hline
\end{tabular}


714 Table 6. The difference in the Sørenson similarity, calculated as vascular - bryophyte, between

715 the communities for the pairs of regions that had both taxa.

716

\begin{tabular}{lrrlllllll} 
& \multicolumn{1}{l}{ ALP } & \multicolumn{1}{l}{ CBR } & \multicolumn{1}{l}{ GNP } & IPA & NAP & NOS & PYR & SBC & SCT \\
CBR & 0.0020 & & & & & & & & \\
GNP & -0.0057 & 0.0221 & & & & & & & \\
IPA & -0.0033 & 0.0057 & -0.0340 & & & & & & \\
NAP & 0.0105 & -0.0017 & 0.0017 & 0.0002 & & & & & \\
NOS & 0.0110 & 0.0098 & 0.0078 & 0.0035 & -0.0046 & & & & \\
PYR & -0.0343 & -0.0042 & -0.0013 & -0.0050 & 0.0020 & -0.0125 & & & \\
SBC & -0.0060 & -0.0014 & 0.0056 & 0.0035 & 0.0010 & 0.0009 & -0.0033 & & \\
SCT & 0.0218 & -0.0220 & 0.0012 & 0.0016 & 0.0226 & 0.0233 & 0.0079 & -0.0042 & \\
SOS & 0.0106 & -0.0179 & 0.0032 & 0.0005 & 0.0251 & 0.0281 & -0.0101 & -0.0019 & 0.0497
\end{tabular}


719 Table 7. General Linear Models of the four nonmetric multidimensional scaling (NMDS)

720 ordination axis centroids of the regions on the geographic and climatic variables for the vascular and bryophyte species. Geographic: continent (Europe and North America); latitude (midlatitude and oroarctic); significant Moran eigenvector - Moran1; distance to all 12 others Dist12; and distance to three nearest neighbors - Dist3. Climatic: by time (mean Annual or Cold, Warm, Dry or Wet quarter) P - preciptiation; $\mathrm{T}$ - temperature. Not entering any model: AnnualP, AnnualT, WarmT, DryP.

\begin{tabular}{|c|c|c|c|c|c|}
\hline & \multicolumn{2}{|l|}{ Vascular } & & \multicolumn{2}{|l|}{ Bryophyte } \\
\hline NMDS1 & Contribution & $\mathrm{p}$ & & \multicolumn{2}{|l|}{ no terms in the model } \\
\hline Moran1 & 0.469 & $<0.000$ & & & \\
\hline Dist3 & 0.359 & 0.001 & & & \\
\hline Error & 0.173 & & & & \\
\hline Adjusted $\mathrm{R}^{2}$ & \multicolumn{2}{|l|}{0.793} & & & \\
\hline NMDS2 & Contribution & $p$ & & \multicolumn{2}{|l|}{ no terms in the model } \\
\hline Dist12 & 0.610 & 0.010 & & & \\
\hline WarmP & 0.243 & 0.002 & & & \\
\hline Error & 0.146 & & & & \\
\hline Adjusted $\mathrm{R}^{2}$ & \multicolumn{2}{|l|}{0.824} & & & \\
\hline NMDS3 & Contribution & $p$ & & Contribution & $p$ \\
\hline ColdP & 0.480 & 0.005 & Latitude & 0.747 & $<0.000$ \\
\hline Dist12 & 0.139 & 0.036 & Moran1 & 0.195 & 0.025 \\
\hline Error & 0.382 & & Error & 0.059 & \\
\hline Adjusted $\mathrm{R}^{2}$ & \multicolumn{2}{|l|}{0.542} & & \multicolumn{2}{|l|}{0.925} \\
\hline NMDS4 & Contribution & $\mathrm{p}$ & & Contribution & $p$ \\
\hline Moran1 & 0.545 & $<0.000$ & WetP & 0.417 & 0.044 \\
\hline Dist3 & 0.208 & 0.087 & Error & 0.584 & \\
\hline Continent & 0.111 & $<0.000$ & & & \\
\hline WarmP & 0.108 & 0.011 & & & \\
\hline ColdT & 0.014 & 0.005 & & & \\
\hline ColdP & 0.002 & 0.038 & & & \\
\hline Error & 0.011 & & & & \\
\hline Adjusted $\mathrm{R}^{2}$ & & 0.977 & & \multicolumn{2}{|l|}{0.344} \\
\hline \multicolumn{6}{|c|}{ Total strength, contribution: } \\
\hline Geography & 1.90 & & & 0.95 & \\
\hline Region & 0.11 & & & 0.75 & \\
\hline Distance & 1.79 & & & 0.20 & \\
\hline Climate & 0.84 & & & 0.42 & \\
\hline Precipitat & 0.83 & & & 0.42 & \\
\hline Temperat & ure $\quad 0.01$ & & & $<0.00$ & \\
\hline Summed Adj & $2^{2}$ (of 4.0) & 3.14 & & 1.27 & \\
\hline
\end{tabular}




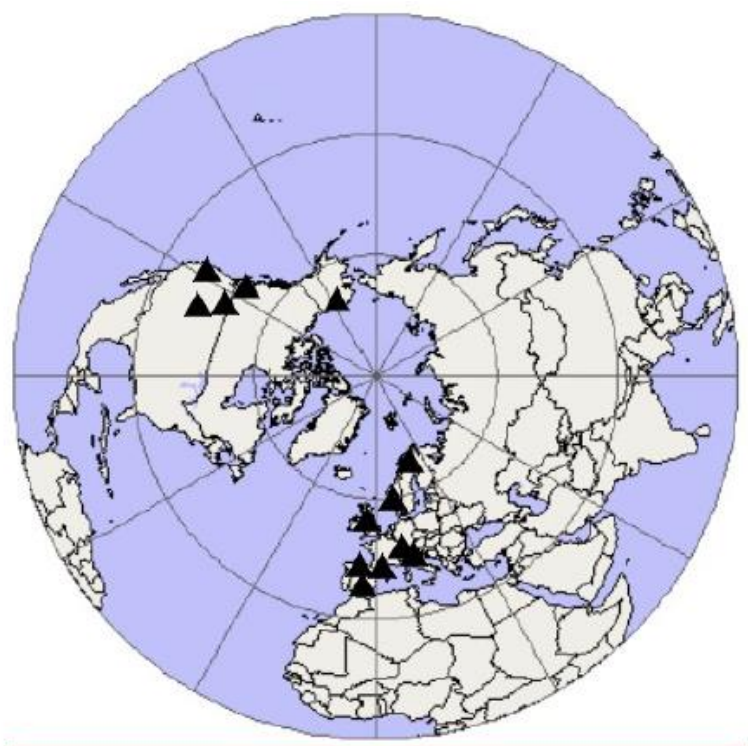

768

Figure 1. The locations of the 13 regions identified in Table 1 shown on an azimuthal 769 equidistant projection. 

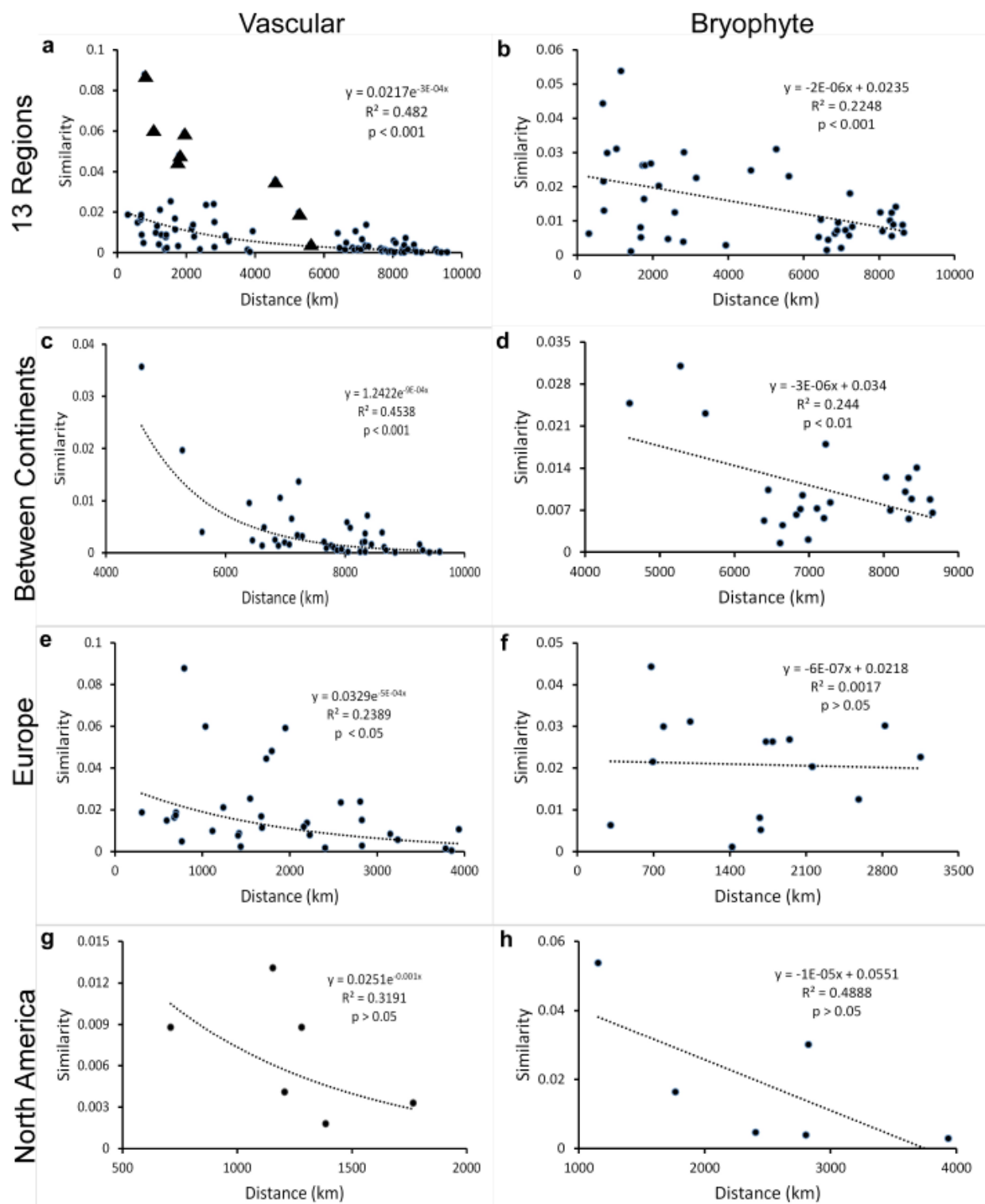

Figure 2. The mean Sørenson similarity metrics of all the pairs of plots between regions graphed against the distance $(\mathrm{km})$ between them. For the vascular species, similarity-distance relations were fit with an exponential equation, while the bryophyte relations were linear. The $\mathrm{p}$ values were calculated using a Mantel randomization. The triangles symbols in a are the oroarctic regions. 


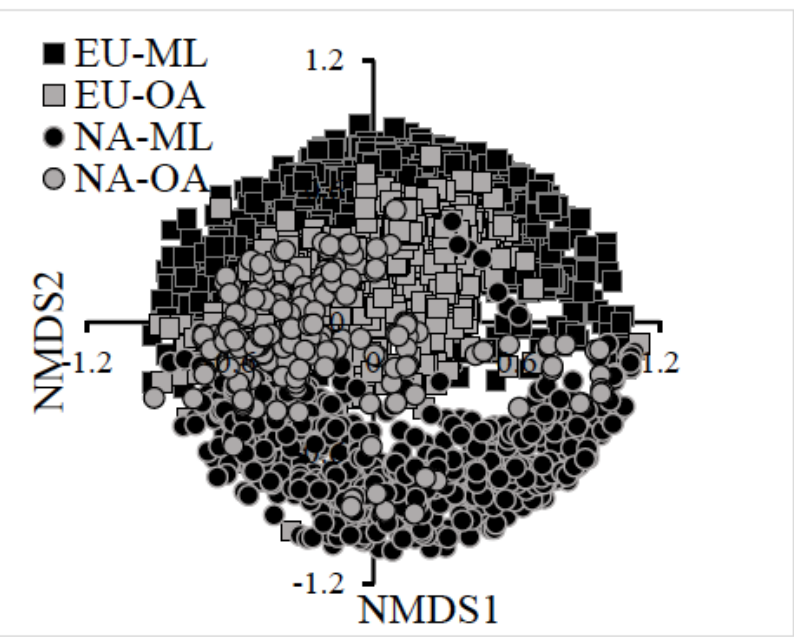

Figure 3. Nonmetric multidimensional scaling (NMDS) results plotted in two dimensions for a reduced set of plots for visualization only. Regions are grouped by continent (Europe - EU; North America - NA) and latitude zone ( $\mathrm{ML}$ - midlatitude; $\mathrm{OA}$ - oroarctic).

781

782 